The Egyptian Journal of Hospital Medicine (January 2021) Vol. 82 (3), Page 445-454

\title{
Efficacy of Dexamethasone as A Prophylaxis for Radiation-Induced Pain Flare after Palliative Radiotherapy for Symptomatic Bone Metastases
}

Mai Y. Zaki, Soheir E. Abdelmohsen, Maha L. Zamzam, Marwa A. Suliman*

Clinical Oncology Department, Faculty of Medicine - Suez Canal University, Ismailia, Egypt

*Corresponding Author: Marwa A. Suliman, Mobile: +201007585156, E-mail: marwa_awad2008@yahoo.com

\begin{abstract}
Background: Bone is the most common site for metastases in cancer and may complicate a wide range of malignancies. Radiotherapy is a successful and efficient method for pain palliation and it can prevent the morbidity of bone metastases. Pain flare is a common event, occurring in almost $40 \%$ of the patients that receive palliative radiotherapy. Dexamethasone has shown possibility for prevention of such flare.

Objective: This study aimed to investigate the efficacy of dexamethasone as prophylaxis for radiotherapy-induced pain flare in cases of painful bone metastases.

Patients and Methods: Prospective randomized control trial was conducted at the Oncology and Nuclear Therapy Unit, Suez Canal University Hospital. The study involved 129 patients. Patients with painful bone metastases were divided into two groups, Study group received $8 \mathrm{mg}$ dexamethasone first day of radiotherapy then for three days after finishing treatment, while control group received radiotherapy only.

Results: The mean age in study group was $60.59 \pm 7.64$ years in comparison to $59.85 \pm 7.02$ years in control group. The most common primary sites were breast and prostate cancer. Incidence of pain flare was $8.8 \%$ of patients among study group while $19.7 \%$ of patients among control group. The difference between both groups was statistically non-significant. Conclusion: Dexamethasone does not play a significant role in reducing pain flare after palliative radiotherapy on painful bone metastases.
\end{abstract}

Keywords: Dexamethasone, Pain flare, Radiotherapy, Bone metastases

\section{INTRODUCTION}

Bone is the most common site for metastases. It is a complication of a wide range of malignancies, resulting in significant morbidity and complex demands on healthcare resources. Bone metastases are the most common cause of cancer-related pain ${ }^{(\mathbf{1})}$.

Radiation therapy is a successful way to relieve pain and prevent the spread of bone metastases. Depending on the criteria used, a complete pain response can be achieved from $10 \%$ to $35 \%$ of patients, with overall pain response rates approaching $70 \%{ }^{(2)}$. Pains flare usually occurring in almost $40 \%$ of the patients who receive palliative radiotherapy for symptomatic bone metastases. Radiotherapy is a very effective palliative treatment; however, pain flare has a negative impact on daily functioning and mood of patients. No significant difference was found between patients who experienced pain flare versus who did not in terms of sex, radiation dose, previous systemic therapy or location of area receiving radiotherapy ${ }^{(3)}$. Pain flare is defined as a two-point increase from baseline pain in the pain scale of $0-10$ with no decrease in analgesic intake or increase in analgesic intake by $25 \%$ employing daily oral morphine equivalent with no decrease in pain score ${ }^{(4)}$.

Dexamethasone can be used for prevention of such flare as dexamethasone might decrease this edema and thereby reduce the incidence of pain flare. Multiple studies were conducted both globally and locally including study showing that $26 \%$ of patients enrolled to dexamethasone experienced pain flare versus $35 \%$ of patients who did not receive dexamethasone (5). Besides, a study done in south Egypt cancer institute, Assiut University showed that $16.2 \%$ of patients who received dexamethasone developed pain flare while $38 \%$ of patients who did not receive dexamethasone developed pain flare ${ }^{(6)}$. As well as other ongoing studies ${ }^{(7)}$. 
Various methods and scales can be used in assessing the pain, numeric rating scale (NRS-11) was used as it is simple and moderately accurate encouraging frequent assessment of pain required in this study ${ }^{(8)}$. Therefore, we studied the efficacy of dexamethasone as prophylaxis for radiotherapy-induced pain flare in cases of painful bone metastases.

\section{PATIENTS AND METHODS}

It is two arms prospective randomized control trial study evaluating efficacy of dexamethasone as prophylaxis for pain flare occurring after palliative radiotherapy among cancer patients with painful bone metastases.

The study was conducted at Oncology and Nuclear Medicine Unit, Suez Canal University Hospital, Ismailia governorate, Egypt. The inclusion of participants was restricted to those who are 18 years or older with confirmed uncomplicated painful bone metastases where primary malignancy is solid tumor \& pain intensity from 2-8 as used in numeric rating scale (NRS- 11).

Data were collected through patients' medical records and examination was done to assess performance status, site and severity of tenderness. A structural electronic form that was established using Microsoft excel (version 2016) to collect the required data. The age, gender, cancer type, chronic illness, type of analgesics, previous bone irradiation, investigations revealing bone metastases and full lab were collected from the archived records in the oncology clinic. Patients were randomly divided into two groups: Study group where patients were given dexamethasone on first day of treatment (day 0) then for three days after completion of radiotherapy schedule (day1, day2, day3) and Control group where patients received radiotherapy schedule without dexamethasone. Pain assessment was done using (NRS-11) on first day of treatment (day 0) then for ten days after completion of radiotherapy schedule (day1-day10).

\section{Ethical consideration:}

The study proposal was first approved by the Research Ethics Committee of Faculty of Medicine, Suez Canal University. The official agreements of the general manager of Suez Canal University Hospital and the Head of Oncology and Nuclear Therapy Unit were obtained to access the required data from the patient's medical records. Confidentiality of the obtained data was strictly kept the anonymousness of patient information was ensured throughout the study conduction. Additionally, the accessed data was used for the purpose of this research only. Every patient signed an informed written consent for acceptance of the operation.

\section{Statistical analysis:}

Data were verified, coded by the researcher and analyzed using IBM-SPSS Statistics for windows, version 23.0 (Copyright IBM Corp., Armonk, N.Y., USA, 2015). Descriptive statistics: Means, standard deviations, medians, ranges and percentages were calculated. Tests of significances: chi-square test was used to compare the difference in distribution of frequencies among different groups, for continuous variables, independent t-test analysis was used to compare the means of dichotomous data. There was no specific calculation of the sample size. A significant $\mathrm{p}$-value was considered when it is equal or less than 0.05 .

\section{RESULTS}

129 patients with painful bone metastases were divided into 2 groups, study group 68 patients and control group 61 patients. Study group received $8 \mathrm{mg}$ dexamethasone first day of radiotherapy then for three days after finishing treatment, while control group received radiotherapy only. Study group consisted of 28 males $(41.2 \%)$ and 40 females $(58.8 \%)$, while control group consisted of 26 males (42.6\%) and 35 females $(57.4 \%)$. There was no statistically significant difference in gender distribution between groups $(\mathrm{p}=$ 0.868 ). The mean age in study group was $60.59 \pm 7.64$ years in comparison to $59.85 \pm 7.02$ years in control group, with statistically non-significant difference between groups $(\mathrm{p}=0.571)($ Table1 $)$. 
Table (1): Demographic data of both groups

\begin{tabular}{|c|c|c|c|c|c|c|c|}
\hline & \multicolumn{2}{|c|}{$\begin{array}{c}\text { Study } \\
(\mathrm{n}=68)\end{array}$} & \multicolumn{2}{|c|}{$\begin{array}{l}\text { Control } \\
(n=61)\end{array}$} & \multirow[t]{2}{*}{ Both } & \multirow{2}{*}{$\begin{array}{c}\text { Test of } \\
\text { Sig. }\end{array}$} & \multirow[t]{2}{*}{$\mathbf{P}$} \\
\hline & No. & $\%$ & No. & $\%$ & & & \\
\hline \multicolumn{8}{|l|}{ Gender } \\
\hline Male & 28 & 41.2 & 26 & 42.6 & & $\chi^{2}=$ & \multirow{2}{*}{0.868} \\
\hline Female & 40 & 58.8 & 35 & 57.4 & & 0.028 & \\
\hline \multicolumn{8}{|l|}{ Age (years) } \\
\hline Min. - Max. & \multirow{3}{*}{\multicolumn{2}{|c|}{$\begin{array}{c}37.0-76.0 \\
60.59 \pm 7.64 \\
60.50\end{array}$}} & \multirow{3}{*}{\multicolumn{2}{|c|}{$\begin{array}{c}46.0-73.0 \\
59.85 \pm 7.02 \\
61.0\end{array}$}} & \multirow{3}{*}{$60.24 \pm 7.33$} & & \multirow{3}{*}{0.571} \\
\hline Mean \pm SD & & & & & & $\mathrm{t}=$ & \\
\hline Median & & & & & & & \\
\hline
\end{tabular}

$* \chi^{2}$ : Chi square test $\mathrm{t}$ : Student t-test $* * \mathrm{p}: \mathrm{p}$ value for comparing between the studied groups

The most common primary sites among study group were breast (45.6\%), prostate $(22.1 \%)$, lung and bladder (8.8\%), Unknown origin (5.9\%) and HCC and Colon (4.4\%). While, the most common primary sites among control group were breast (47.5\%), prostate (19.7\%), lung (13.1\%), bladder and HCC (8.2\%) and sarcoma and colon $(1.6 \%)$. The difference between groups was statistically non-significant (Table 2).

Table (2): Frequency of primary sites between both groups

\begin{tabular}{lcccccc}
\multicolumn{1}{c}{$\begin{array}{c}\text { Diagnosis } \\
\text { (type of cancer) }\end{array}$} & \multicolumn{2}{c}{$\begin{array}{c}\text { Study } \\
(\mathbf{n = 6 8})\end{array}$} & \multicolumn{2}{c}{$\begin{array}{c}\text { Control } \\
(\mathbf{n = 6 1})\end{array}$} & $\chi^{\mathbf{2}}$ & P \\
\cline { 2 - 6 } & No. & \% & No. & \% & & \\
\hline Unknown origin & 4 & 5.9 & 0 & 0.0 & 3.703 & ${ }^{{ }^{F E}} \mathrm{p}=0.121$ \\
Breast & 31 & 45.6 & 29 & 47.5 & 0.049 & 0.824 \\
Lung & 6 & 8.8 & 8 & 13.1 & 0.612 & 0.434 \\
HCC & 3 & 4.4 & 5 & 8.2 & 0.792 & ${ }^{\mathrm{FE}} \mathrm{p}=0.575$ \\
Bladder & 6 & 8.8 & 5 & 8.2 & 0.016 & 0.899 \\
Colon & 3 & 4.4 & 1 & 1.6 & 0.823 & ${ }^{\mathrm{FE}} \mathrm{p}=0.621$ \\
Prostate & 15 & 22.1 & 12 & 19.7 & 0.111 & 0.739 \\
Sarcoma & 0 & 0.0 & 1 & 1.6 & 1.123 & ${ }^{\mathrm{FE}} \mathrm{p}=0.473$ \\
\hline
\end{tabular}

$* \chi^{2}$ : Chi square test $\quad$ FE: Fisher Exact $* *$ p: $\mathrm{p}$ value for comparing between the studied groups

The most frequent radiated sites among the study group were dorsal vertebrae (27.9\%), pelvis (22.1\%), lumbar vertebrae $(13.2 \%)$, femur $(10.3 \%)$, shoulder $(8.8 \%)$, humerus $(7.4 \%)$, tibia and cervical vertebrae $(4.4 \%)$, and sternum (1.5\%). While in the control group, the most common primary sites were lumbar vertebrae (29.5\%), dorsal vertebrae $(21.3 \%)$, pelvis $(18.0 \%)$, femur $(9.8 \%)$, cervical vertebrae $(8.2 \%)$, shoulder $(8.2 \%)$, humerus $(1.6 \%)$, tibia $(3.3 \%)$, and sternum $(0 \%)$. The difference between groups was statistically non-significant. Lumbar vertebrae were statistically significant (Table 3). 
Table (3): Site of bone metastases between both groups

\begin{tabular}{|c|c|c|c|c|c|c|}
\hline \multirow{2}{*}{ Radiation } & \multicolumn{2}{|c|}{ Study $(n=68)$} & \multicolumn{2}{|c|}{ Control $(n=61)$} & \multirow{2}{*}{$\chi^{2}$} & \multirow{2}{*}{$\mathbf{P}$} \\
\hline & No. & $\%$ & No. & $\%$ & & \\
\hline \multicolumn{7}{|l|}{ Site } \\
\hline Tibia & 3 & 4.4 & 2 & 3.3 & 0.111 & ${ }^{\mathrm{FE}} \mathrm{p}=1.000$ \\
\hline Sternum & 1 & 1.5 & 0 & 0.0 & 0.904 & ${ }^{\mathrm{FE}_{\mathrm{p}}}=1.000$ \\
\hline Shoulder & 6 & 8.8 & 5 & 8.2 & 0.016 & 0.899 \\
\hline Pelvis & 15 & 22.1 & 11 & 18.0 & 0.324 & 0.569 \\
\hline Lumbar vertebrae & 9 & 13.2 & 18 & 29.5 & $5.145^{*}$ & $0.023^{*}$ \\
\hline Humerus & 5 & 7.4 & 1 & 1.6 & 2.367 & 0.212 \\
\hline Femur & 7 & 10.3 & 6 & 9.8 & 0.007 & 0.931 \\
\hline Dorsal vertebrae & 19 & 27.9 & 13 & 21.3 & 0.758 & 0.384 \\
\hline Cervical vertebrae & 3 & 4.4 & 5 & 8.2 & 0.792 & 0.475 \\
\hline
\end{tabular}

$* \chi^{2}$ : Chi square test MC: Monte Carlo FE: Fisher Exact ** p: $\mathrm{p}$ value for comparing between the studied groups *: Statistically significant at $\mathrm{p} \leq 0.0$

In study group, $85.3 \%$ of patients received 30 gray $/ 10$ fractions, $10.3 \%$ of patients received 20 gray $/ 5$ fractions, and $4.4 \%$ of patients received 24 gray / 6 fractions. In control group, $82 \%$ of patients received 30 gray $/ 10$ fractions, $13.1 \%$ of patients received 20 grays $/ 5$ fractions and $4.9 \%$ of patients received 24 grays/ 6 fractions. The difference between groups was statistically non-significant (Table 4).

Table (4): Radiation dose received for bone metastases between both groups

\begin{tabular}{cccccc}
\hline \multirow{2}{*}{ Radiation } & \multicolumn{2}{c}{$\begin{array}{c}\text { Study } \\
(\mathbf{n = 6 8})\end{array}$} & $\begin{array}{c}\text { Control } \\
(\mathbf{n}=61)\end{array}$ & \multirow{2}{*}{$\chi^{2}$} & P \\
\cline { 2 - 4 } & No. & No. $\%$ & $\%$ \\
\hline
\end{tabular}

\begin{tabular}{lcccccc}
\hline Dose & & & & & & \\
$30 / 10$ & 58 & 85.3 & 50 & 82.0 & & \\
$20 / 5$ & 7 & 10.3 & 8 & 13.1 & 0.396 & ${ }^{{ }^{M}} \mathrm{p}=$ \\
$24 / 6$ & 3 & 4.4 & 3 & 4.9 & & 0.934 \\
\hline
\end{tabular}

$* \chi^{2}$ : Chi square test MC: Monte Carlo

FE: Fisher Exact $\quad * *$ p: p value for comparing between the studied groups

*: Statistically significant at $\mathrm{p} \leq 0.05$

\section{At presentation}

- Performance (1): $16.2 \%$ of patients in study group and $8.2 \%$ of patients in control group. The difference between groups was statistically significant.

- Performance (2): $54.4 \%$ of patients in study group and $29.5 \%$ of patients in control group. The difference between groups was statistically significant.

- Performance (3): $29.4 \%$ of patients in study group and $62.3 \%$ of patients in control group. The difference between groups was statistically significant (Table 5).

\section{After therapy:}

- Performance (1): $32.4 \%$ of patients in study group and $16.4 \%$ of patients in control group. The difference between groups was statistically significant.

- Performance (2): $42.6 \%$ of patients in study group and $34.4 \%$ of patients in control group. The difference between groups was statistically significant.

- Performance (3): $25.0 \%$ of patients in study group and $49.2 \%$ of patients in control group. The difference between groups was statistically significant (Table 5).

A statistically significant improvement of ECOG performance of patients after radiotherapy in both control and study groups. The difference between groups was statistically significant (Table 5). 
Table (5): Performance status before and after therapy

\begin{tabular}{|c|c|c|c|c|c|c|}
\hline \multirow[t]{2}{*}{ Performance } & \multicolumn{2}{|c|}{$\begin{array}{c}\text { Study } \\
(\mathrm{n}=68)\end{array}$} & \multicolumn{2}{|c|}{$\begin{array}{l}\text { Control } \\
(n=61)\end{array}$} & \multirow[t]{2}{*}{$\square^{\square}$} & \multirow[t]{2}{*}{$\mathbf{P}$} \\
\hline & No. & $\%$ & No. & $\%$ & & \\
\hline \multicolumn{7}{|c|}{ At presentation } \\
\hline 1 & 11 & 16.2 & 5 & 8.2 & & \\
\hline 2 & 37 & 54.4 & 18 & 29.5 & $14.061^{*}$ & $0.001^{*}$ \\
\hline 3 & 20 & 29.4 & 38 & 62.3 & & \\
\hline \multicolumn{7}{|l|}{ After therapy } \\
\hline 1 & 22 & 32.4 & 10 & 16.4 & & \\
\hline \multirow[t]{2}{*}{2} & 29 & 42.6 & 21 & 34.4 & $9.022^{*}$ & $0.011^{*}$ \\
\hline & 17 & 25.0 & 30 & 49.2 & & \\
\hline
\end{tabular}

$* \chi^{2}$ : Chi square test $\mathrm{p}: \mathrm{p}$ value for comparing between the studied groups *: Statistically significant at $\mathrm{p} \leq 0.05$

Toxicity: $10.3 \%$ of patients in study group and $11.5 \%$ of patients in control group developed toxicity that was upper GI toxicity (Table 6).

Table (6): RTOG toxicity grade between both groups

\begin{tabular}{|c|c|c|c|c|c|c|}
\hline \multirow[t]{2}{*}{ RT Toxicity } & \multicolumn{2}{|c|}{$\begin{array}{c}\text { Study } \\
(n=68) \\
\end{array}$} & \multicolumn{2}{|c|}{$\begin{array}{l}\text { Control } \\
(\mathrm{n}=61) \\
\end{array}$} & \multirow[t]{2}{*}{$\chi^{2}$} & \multirow[t]{2}{*}{$\mathbf{P}$} \\
\hline & No. & $\%$ & No. & $\%$ & & \\
\hline & 61 & 89.7 & 54 & 88.5 & \multirow{2}{*}{0.046} & \multirow{2}{*}{0.829} \\
\hline Yes & 7 & 10.3 & 7 & 11.5 & & \\
\hline Lower GI grade 1 & 2 & 2.9 & 2 & 3.3 & 0.012 & ${ }^{\mathrm{FE}} \mathrm{p}=1.000$ \\
\hline Upper GI grade1 & 3 & 4.4 & 3 & 4.9 & 0.019 & ${ }^{\mathrm{FE}} \mathrm{p}=1.000$ \\
\hline Lower GI grade2 & 1 & 1.5 & 0 & 0.0 & 0.904 & ${ }^{\mathrm{FE}} \mathrm{p}=1.000$ \\
\hline Pharynx grade1 & 1 & 1.5 & 0 & 0.0 & 0.904 & ${ }^{\mathrm{FE}} \mathrm{p}=1.000$ \\
\hline Hematological grade3 & 0 & 0.0 & 1 & 1.6 & 1.123 & ${ }^{\mathrm{FE}} \mathrm{p}=0.473$ \\
\hline Genitourinary grade 1 & 0 & 0.0 & 1 & 1.6 & 1.123 & ${ }^{F E} \mathrm{p}=0.473$ \\
\hline
\end{tabular}

$* \chi^{2}$ : Chi square test FE: Fisher Exact $\quad * *$ p: $p$ value for comparing between the studied groups.

There was no statistical difference between both groups in relation to pain relief and primary cancer site, radiation site and dose. However, there was statistical difference between both groups in relation to pain relief and patient's performance that improved after receiving radiotherapy (Table 7). 
Table (7): Relation between pain relief and different parameters in each group

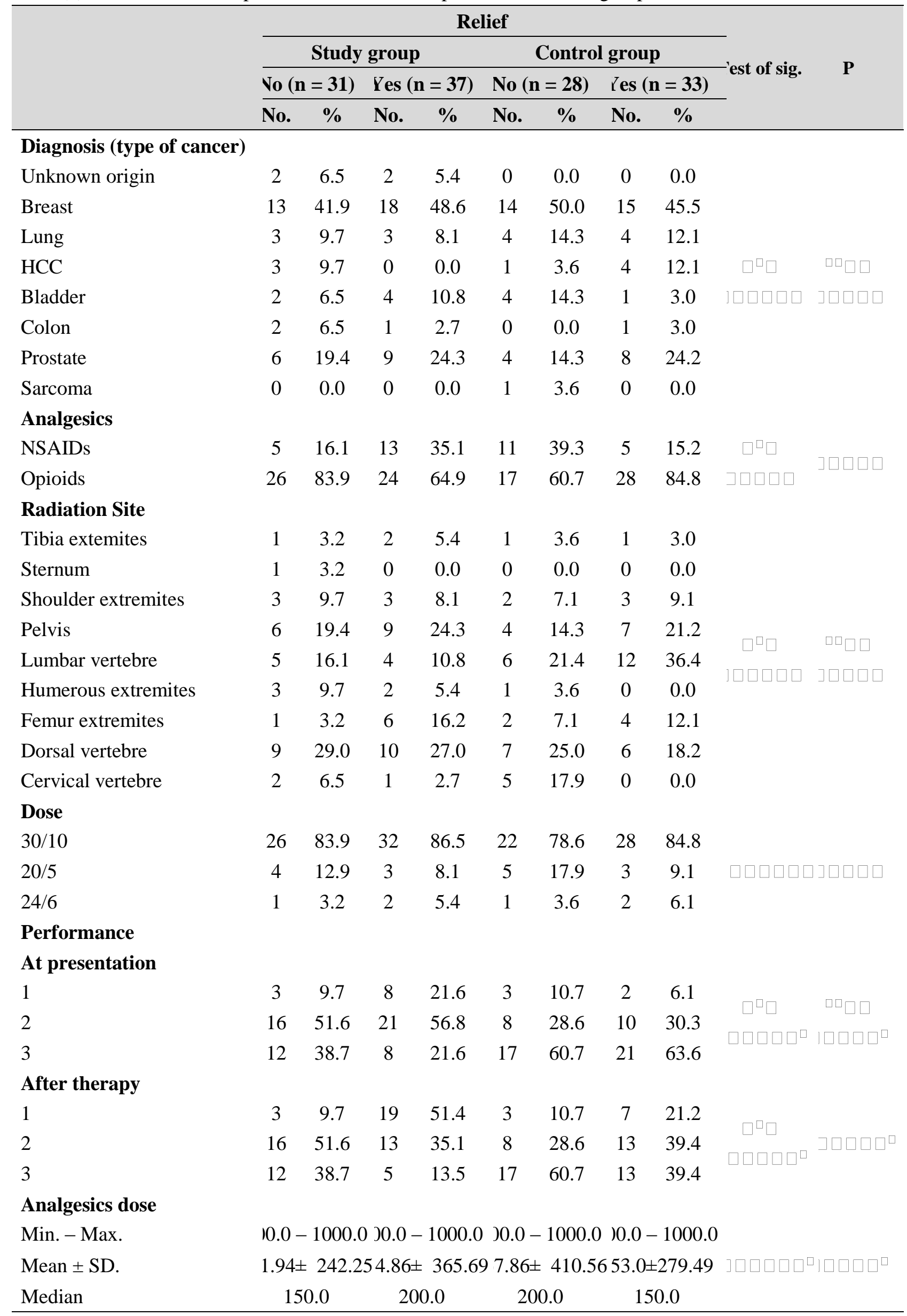

$* \chi^{2}$ : Chi square test $\quad$ MC: Monte Carlo $\quad \mathrm{H}: \mathrm{H}$ for Kruskal Wallis test ** $\mathrm{p}: \mathrm{p}$ value for comparing between the studied categories *: Statistically significant at $\mathrm{p} \leq 0.05$. There was no statistical difference between both groups in relation to pain flare and primary cancer site, radiation site, dose or performance (Table 8). 
Table (8): Relation between pain (flare) and different parameters in each group

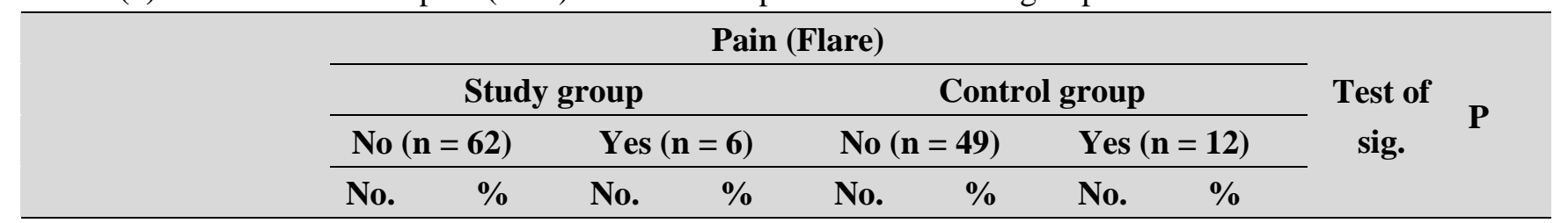

\section{Diagnosis (type of cancer)}

$\begin{array}{lccccccccc}\text { Unknown origin } & 4 & 6.5 & 0 & 0.0 & 0 & 0.0 & 0 & 0.0 & \\ \text { Breast } & 28 & 45.2 & 3 & 50.0 & 22 & 44.9 & 7 & 58.3 & \\ \text { Lung } & 5 & 8.1 & 1 & 16.7 & 8 & 16.3 & 0 & 0.0 & \\ \text { HCC } & 3 & 4.8 & 0 & 0.0 & 4 & 8.2 & 1 & 8.3 & \square \square \square \quad{ }^{{ }^{2}} \mathrm{p}= \\ \text { Bladder } & 6 & 9.7 & 0 & 0.0 & 3 & 6.1 & 2 & 16.7 & \square \square \square \square[0.847 \\ \text { Colon } & 3 & 4.8 & 0 & 0.0 & 1 & 2.0 & 0 & 0.0 & \\ \text { Prostate } & 13 & 21.0 & 2 & 33.3 & 10 & 20.4 & 2 & 16.7 \\ \text { Sarcoma } & 0 & 0.0 & 0 & 0.0 & 1 & 2.0 & 0 & 0.0\end{array}$

\section{Analgesics}

NSAIDs

$\begin{array}{llllllllll}17 & 27.4 & 1 & 16.7 & 14 & 28.6 & 2 & 16.7 & \square \square \square & { }^{\mathrm{MC}} \mathrm{p}= \\ 45 & 72.6 & 5 & 83.3 & 35 & 71.4 & 10 & 83.3 & \square \square \square \square \square & 0.888\end{array}$

Opioids

\section{Radiation site}

Tibia extemites

Sternum

Shoulder extremites

Pelvis

$$
3
$$$$
\begin{array}{llll}
4.8 & 0 & 0.0 & 1
\end{array}
$$$$
\begin{array}{lll}
2.0 & 1 & 8.3
\end{array}
$$$$
\begin{array}{llllllll}
1 & 1.6 & 0 & 0.0 & 0 & 0.0 & 0 & 0.0
\end{array}
$$$$
6
$$$$
9.7
$$$$
0.0 \quad 5
$$$$
\begin{array}{lll}
10.2 & 0 & 0.0
\end{array}
$$

Lumbar vertebre

13

$21.0 \quad 2$

$33.3 \quad 8$

$\begin{array}{lll}16.3 & 3 & 25.0\end{array}$

9

14.5

$0.0 \quad 16$

$32.7 \quad 2$

Humerous extremites

$\begin{array}{llll}8.1 & 0 & 0.0 & 1\end{array}$

$2.0 \quad 0$

0.0

Femur extremites

6

$9.7 \quad 1$

$16.7 \quad 3$

$6.1 \quad 3$

Dorsal vertebre

$\begin{array}{lllll}16 & 25.8 & 3 & 50.0 & 11\end{array}$

$\begin{array}{lll}22.4 & 2 & 16.7\end{array}$

Cervical vertebre

4.8

$0.0 \quad 4$

8.21

\section{Dose}

$30 / 10$

$20 / 5$

$24 / 6$

$\begin{array}{ccccc}54 & 87.1 & 4 & 66.7 & 43 \\ 6 & 9.7 & 1 & 16.7 & 5 \\ 2 & 3.2 & 1 & 16.7 & 1\end{array}$

$87.8 \quad 7$

58.3

$10.2 \quad 3 \quad 25.0$

$\begin{array}{lll}2.0 & 2 & 16.7\end{array}$

${ }^{\mathrm{MC}} \mathrm{p}=$ 0.601

\section{Performance}

\begin{tabular}{|c|c|c|c|c|c|c|c|c|c|c|}
\hline 1 & 10 & 16.1 & 1 & 16.7 & 5 & 10.2 & 0 & 0.0 & \multirow{2}{*}{$\square^{\square} \square$} & \multirow{2}{*}{${ }^{\mathrm{MC}} \mathrm{p}=$} \\
\hline 2 & 34 & 54.8 & 3 & 50.0 & 13 & 26.5 & 5 & 41.7 & & \\
\hline 3 & 18 & 29.0 & 2 & 33.3 & 31 & 63.3 & 7 & 58.3 & \multicolumn{2}{|c|}{ ] $\square \square \square \square \square$ 0.009* } \\
\hline \multicolumn{11}{|c|}{ After therapy } \\
\hline 1 & 20 & 32.3 & 2 & 33.3 & 8 & 16.3 & 2 & 16.7 & \multirow{3}{*}{$\begin{array}{c}\square^{\square} \square \\
\square \square \square \square \square\end{array}$} & \multirow{3}{*}{0.123} \\
\hline 2 & 26 & 41.9 & 3 & 50.0 & 16 & 32.7 & 5 & 41.7 & & \\
\hline 3 & 16 & 25.8 & 1 & 16.7 & 25 & 51.0 & 5 & 41.7 & & \\
\hline \multicolumn{11}{|c|}{ Analgesics dose } \\
\hline Min. - Max. & \multirow{2}{*}{\multicolumn{2}{|c|}{$\begin{array}{l}100.0-1000.0 \\
38.71 \pm 326.36\end{array}$}} & \multicolumn{2}{|c|}{$150.0-1000.0$} & \multicolumn{2}{|c|}{$100.0-1000.0$} & \multicolumn{2}{|c|}{$100.0-1000.0$} & \multirow{3}{*}{$\square \square$} & \multirow{3}{*}{0.768} \\
\hline Mean \pm SD & & & 08.33 & 339.73 & 72.45 & 371.94 & 66.67 & 301.76 & & \\
\hline Median & \multicolumn{2}{|c|}{200.0} & \multicolumn{2}{|c|}{175.0} & \multicolumn{2}{|c|}{200.0} & \multicolumn{2}{|c|}{150.0} & & \\
\hline
\end{tabular}

\section{At presentation}

* $\chi^{2}$ : Chi square test MC: Monte Carlo H: H for Kruskal Wallis test

** $\mathrm{p}$ : $\mathrm{p}$ value for comparing between the studied categories *: Statistically significant at $\mathrm{p} \leq 0.05$. 
Pain flare: Incidence of pain flare was $8.8 \%$ among patients of study group, while $19.7 \%$ among patients of control group. The difference between groups was statistically non-significant (Figure 1).

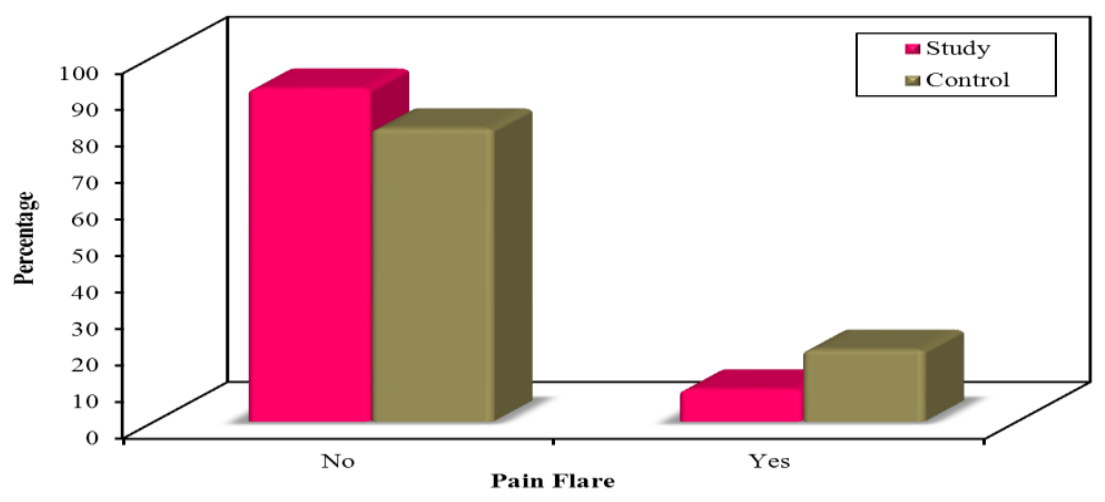

Figure (1): Pain flare.

Onset of pain flare at day 1-day5 was 83.3\% among patients of both groups. Onset of pain flare at day 6-day 10 was $16.7 \%$ among patients of both groups. The difference between groups was statistically non-significant (Figure 2).

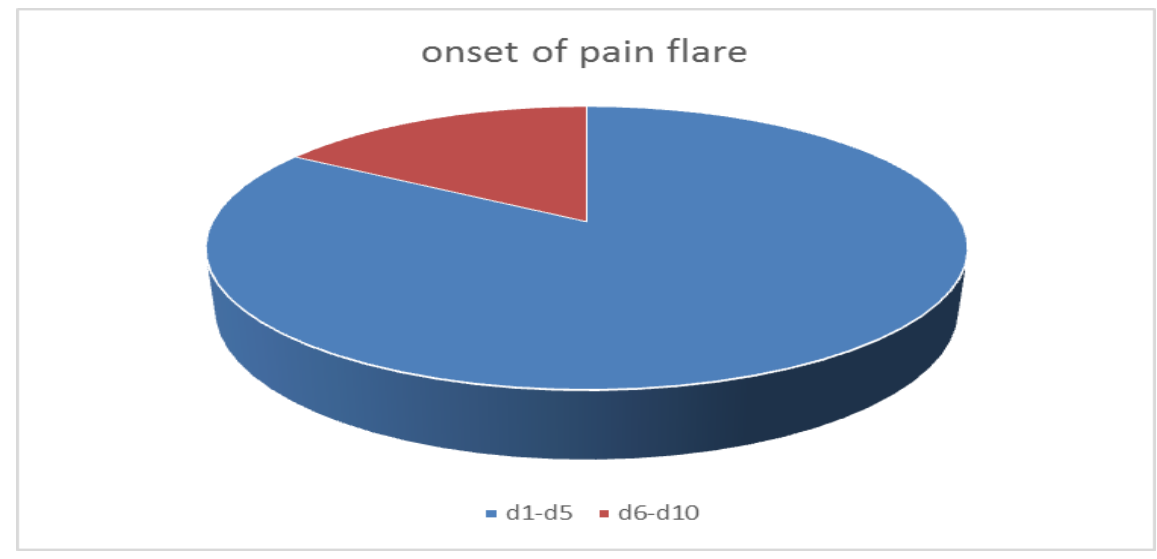

Figure (2): Onset of pain flare.

\section{DISCUSSION}

Pain flare is believed to affect more than one third of patients with painful pain metastases after receiving palliative radiotherapy, whether radiotherapy was delivered in single or multiple fractions ${ }^{(\boldsymbol{9})}$.

Until now no effective treatment available for treatment of pain flare. Thus, a new safe and effective treatment is obviously warranted. Periosteal edema of the irradiated bone is thought to be the cause of pain flare. Therefore, dexamethasone, with its anti-inflammatory effect, may be a suitable drug in minimizing edema.

In this study, we investigated the efficacy of dexamethasone as prophylaxis for pain flare after palliative radiotherapy of painful bone metastases. The study was conducted at Oncology Department, Suez Canal University Hospital during the period from December 2018 to July 2019.
Regarding age of the studied population, the mean age of the study participants was $60.24 \pm 7.33$ years; however the study done in Spain, the mean age was $66.1 \pm 11.75$ years ${ }^{(10)}$, study in Canada with mean age 66.5 years ${ }^{(11)}$, while both Assuit and Mansoura studies had mean age of 55 and 57 years respectively ${ }^{(6,12)}$. This matches global mean age of bone metastases, which is 64 years ${ }^{(13)}$.

Regarding gender of the studied population, $58.1 \%$ of patients were females $41.8 \%$ of patients were males. This also matches global female predominance representing $65.1 \%$ of bone metastases. Two similar studies done in Egypt had number of female patients more than male patients ${ }^{(6,12)}$. while study done in Spain male patients were of $65.9 \%$ and female patients were $34 \%{ }^{(13)}$, however study in Canada had equal number of both male and female patients ${ }^{(11)}$. These differences are influenced by the primary site of bone metastases. 
Our results showed that $47.5 \%$ of studied patient had breast cancer followed by prostate then lung cancer. Bone metastasis incidence was highly variable depending on the primary tumor type, with prostate cancer patients at highest risk of developing bone metastases, followed by patients with lung, renal or breast cancer ${ }^{(\mathbf{1 3})}$. However, in Egypt breast cancer is the second most common cancer after liver, which caused this difference ${ }^{(14)}$. Another two Egyptian studies done in Assuit and Mansoura revealed similar results where $47.6 \%$ had breast cancer followed by bladder then metastatic of unknown origin in Assiut study and $40.2 \%$ of patients had breast cancer followed by lung and prostate cancer ${ }^{(6,12)}$. Our results also comes in agreement with the study done in Canada where $36.4 \%$ of patients had breast cancer and prostate cancer followed by lung cancer ${ }^{(11)}$, while in Spanish study the most common type was lung cancer counting for $31 \%$ followed by prostate cancer then breast cancer ${ }^{(10)}$. Possible reason is due to increased incidence of breast cancer and lack of compliance and screening tests are recommended ${ }^{(\mathbf{1 5})}$.

Spine is the most common radiated site (51.9\%) distributed as $24.8 \%$ dorsal spine, $20.9 \%$ lumbar spine followed by pelvis counting for $20.1 \%$. This is similar to Assuit study where $46.9 \%$ of radiated sites were spine followed by pelvis of $25.2 \%$ (6) and Mansoura study with $41.1 \%$ spine followed by $33 \%$ pelvis ${ }^{(12)}$. This can be explained, as Spine was the most frequent site of bone metastases in breast and GI cancers. In prostate cancer the most frequent site were spine and pelvis. In lung cancer, ribs followed by spine were most frequent sites of bone metastases ${ }^{(\mathbf{1 6})}$.

The most common analgesics used by patients in our study were opioids used by $73.6 \%$ of the patients also Assuit study revealed near results where $84.3 \%$ of patients were on opioids (6) while in Mansoura study the majority of patients (57.2\%) were on NSAI drugs ${ }^{(\mathbf{1 2})}$. This may account for difference in accepting opioids and its stigma in different regions in Egypt.

Regarding radiation scheme in our study $83.7 \%$ of patients received 30 gray/10 fractions while these other two studies used only 20 gray $/ 5$ fractions ${ }^{(6,12)}$, which can be reasoned by different standard practice in each hospital or center.

Patients whom developed toxicity accounts for $10.8 \%$. The most common one was gastrointestinal including nausea and GI upset this could be caused by either radiotherapy or dexamethasone however, there was no statistical significance between control and study group.

There are different methods to assess pain, Numeric pain scale was used, which is simple, short and efficient way in assessing the pain, and for this reason we used it in assessing pain flare. In addition, Mansoura study used it ${ }^{(\mathbf{1 2})}$. While other studies used brief pain inventory scale ${ }^{(6,10)}$. In our study, pain flare occurred among $19.7 \%$ of patients in control group and $8.8 \%$ in study group with no statistical significance among both groups as well as no significant relationships were found between the occurrence of pain flare and radiation dose and site, primary cancer site and patients' performance. Pain flare occurred in $83.3 \%$ of patients in the first 5 days after radiotherapy with no statistical significance. This result is similar to the results done in multicenter study in Spain where no significant relationships were found between the occurrence of pain flare and baseline variables, such as gender type, radiation dose, radiation site, primary cancer site, and dexamethasone use ${ }^{(\mathbf{1 0})}$. However, results were statistically significant between both studies from Egypt ${ }^{(6,12)}$. In Mansoura $14.3 \%$ of patients from study group experienced pain flare while $37.5 \%$ of patients from control group experienced pain flare ${ }^{(12)}$, and in Assuit $16.2 \%$ of patients from study group experienced pain flare while $38 \%$ of patients from control group experienced pain flare ${ }^{(\boldsymbol{\sigma})}$. The absence of statistical significance found between the two groups in our study perhaps could be explained due to variation of sample size of the studies, different radiation scheme used for palliative radiotherapy and unknown effect of dexamethasone on pain flare specifically.

Regarding the performance of patients in this study, it showed statistically significant improvement in performance after treatment as well as no 
significant difference between both groups and relationships were found between pain relief and patients' performance.

\section{CONCLUSION}

There was no statistical significance of pain flare incidence among study and control groups. $83.3 \%$ of cases of pain flare occurred during first 5 days after radiotherapy. Efficacy of dexamethasone as prophylaxis for pain flare could not be established.

\section{REFERENCES}

1. Coleman R (2006): Clinical features of metastatic bone disease and risk of skeletal morbidity. Clin Cancer Res., 12 (20 Pt 2): 6243-9.

2. Lutz S, Berk L, Chang E et al. (2011): Palliative radiotherapy for bone metastases: an ASTRO evidence-based guideline. Int J Radiat Oncol Biol Phys., 79 (4): 965-76.

3. Gomez-Iturriaga A, Cacicedo J, Navarro A et al. (2015): Incidence of pain flare following palliative radiotherapy for symptomatic bone metastases: multicenter prospective observational study. BMC Palliat Care, 14: 48-53.

4. Chow E, Ling A, Davis L et al. (2005): Pain flare following external beam radiotherapy and meaningful change in pain scores in the treatment of bone metastases. Radiother Oncol., 75(1):64-9.

5. Chow $\mathrm{E}$, Meyer $\mathrm{R}$, Ding $\mathrm{K}$ et al. (2015): Dexamethasone in the prophylaxis of radiation-induced pain flare after palliative radiotherapy for bone metastases: a double-blind, randomised placebo-controlled, phase 3 trial. Lancet Oncol., 16 (15): 1463-72.

6. Sayed M (2014): The effect of systemic steroids on the incidence of bone pain flare with palliative Irradiation. Middle East J Cancer, 5 (2): 83-9.

7. Westhoff $P$, de Graeff A, Geerling $\mathrm{J}$ et al. (2014): Dexamethasone for the prevention of a pain flare after palliative radiotherapy for painful bone metastases: a multicenter double-blind placebo-controlled randomized trial. BMC Cancer, 14: 347-53.

8. Hartrick C, Kovan J, Shapiro S (): The numeric rating scale for clinical pain measurement: a ratio measure? Pain Pract., 3 (4): 310-6.

9. Hird A, Chow E, Zhang L et al. (2009): Determining the incidence of pain flare following palliative radiotherapy for symptomatic bone metastases: results from three Canadian cancer centers. Int J Radiat Oncol Biol Phys., 75 (1): 193-7.

10. Gomez-Iturriaga A, Cacicedo J, Navarro A et al. (2015): Incidence of pain flare following palliative radiotherapy for symptomatic bone metastases: multicenter prospective observational study. BMC Palliat Care, 14: 48-51.

11. Loblaw D, Wu J, Kirkbride P et al. (2007): Pain flare in patients with bone metastases after palliative radiotherapy--a nested randomized control trial. Support Care Cancer, 15 (4): 451-5.

12. Akl F, Akl M (2015): Dexamethasone as a prophylaxis of pain flare after palliative irradiationof painful bone metastases. Azhar Assiut Med J., 13 (3): 138-42.

13. Hernandez R, Wade S, Reich A et al. (2018): Incidence of bone metastases in patients with solid tumors: analysis of oncology electronic medical records in the United States. BMC Cancer, 18 (1): 44-49.

14. Ibrahim A, Khaled H, Mikhail N et al. (2014): Cancer incidence in Egypt: results of the national population-based cancer registry program. J Cancer Epidemiol., 2014: 437971.

15. Eltwansy M (2018): Early Detection of Breast Cancer : Knowledge, Perception and Barriers among Females : A Cross Sectional Study at Zagazig District. Egypt J Commun Med., 36 (4): 11-22.

16. Kakhki V, Anvari K, Sadeghi $R$ et al. (2013): Pattern and distribution of bone metastases in common malignant tumors. Nucl Med Rev Cent East Eur., 16 (2): 66-9. 